\title{
Language, aging and emotions: a brief review
}

\section{Mini review}

The purpose of this review is to visualize the effects of aging on language processing, particularly in the understanding of texts with emotional impact. This topic is circumscribed in psycholinguistics under the corporalized approach, in which linguistic processing is based on modal simulations that are responsible for the partial activation of sensory-motor and emotional states during our experience with the environment. ${ }^{1}$ For its part, the comprehension of texts with emotional valence has been explained by several models that argue how to combine experiential aspects of the reader and the characteristics of the causal-narrative structure of the text. In this sense, it has been described that the text emotionally affects the reader as if they were observing, as an invisible witness, the development of history. ${ }^{2}$ Thus, our research interest is born from a project whose results show the possible influence of emotions in the understanding of language. Questions arise such as: Do experiential aspects associated with aging influence the way we perceive reality? Does inhibition and emotional regulation during old/mature age affect language comprehension? Do young people and older adults equally understand news stories with emotional value?.

The study of language in the aging and the influence of the emotions is still young and of great projection, considering that emotions are fundamental to understand the behavior throughout the cycle of life and specifically in the eld. ${ }^{3}$ Evidence in cognitive psychology shows important differences in emotional processing between older adults $(\mathrm{OA})$ and young people. First, it has been shown that the lower physiological activation characteristic of OA is associated with less emotional activation. It has been proven that OAs express their emotions less, or make it out of topic; Justified by a restricted capacity for introspection and emotional identification. ${ }^{3}$ It has been found that OAs present less intense and more cautious emotional reactions than young people. ${ }^{4}$ It has been concluded, after years of research, that OAs regulate their emotions better than young people showing less anger and greater positivity in contexts of ambiguity. ${ }^{5-6}$ These evidences have served as a basis for the theory of social-emotional selectivity (TSS) defined as a motivational shift of the OA by product of the psychological phenomenon of finitude of the life cycle, which leads to privileging the optimization and positivization of the told.

Research in psycholinguistics agrees with these findings. It has been found that OA narrate emotional episodes in a more narrow way and with less detail than the young adults ${ }^{7}$ Associated with emotional suppression and dysfunctional physiological correlates that interfere in processes of attention and memory. In different study submitted OA and young people to make a judgment on texts of positive, negative and ambiguous valence. ${ }^{8}$ Their results showed that OAs perceive ambiguous texts more frequently as positive than young people. In the same way it has been demonstrated that older people better regulate their emotions (reporting less anger) by listening to stories from recorded audios that contain comments inappropriate to them. ${ }^{9}$ In addition, electrophysiological evidence demonstrates the utility of the N400 component of ERP in the search for emotional incongruities in narrative contexts ${ }^{10}$ although the findings have only been focused on the young population. In conclusion it seems that OAs differ from

\author{
Volume 2 Issue I - 2017
}

\author{
Carlos Rojas Zepeda, 1,2 Gabriel Lagos \\ Riveros, ${ }^{2,3}$ Karla Salazar Céspedes ${ }^{4}$ \\ 'Department of Linguistics Doctoral Program, University of \\ Concepción, Chile \\ ${ }^{2}$ Department of Health Rehabilitation Sciences, University of \\ Bio Bio, Chile \\ ${ }^{3}$ Department of Research Group on Aging. University of Bio \\ Bio, Chile \\ ${ }^{4}$ Department of English Teaching Training Program. Adventist \\ University of Chile
}

Correspondence: Carlos Rojas Zepeda, Department of Health Rehabilitation Sciences University of Bio Bio, Fernando May Campus, Chile, Tel (56-42) 2463177. Email crojas@ubiobio.cl

Received: July 26, 2017| Published: August 22, 2017

young people, identify and express their emotions with more difficulty but regulate them better.

As has been exemplified, most studies in psycholinguistics compare aspects related to the expression and regulation of emotions between $\mathrm{OA}$ and young people in artificial linguistic contexts. However, the evidence that contrasts the understanding of language between both groups in real news contexts and with emotional valence is limited. In fact, there is little history of the role of emotions in the way OAs understand language in a real information context. Thus, findings in this area would give us indications of how OAs perceive the reality of the world today. Finally, it should be noted that the number of programs for OA that promote active aging are numerous, however a large number of older adults do not participate in them. ${ }^{11}$ Undoubtedly, to show that aging influences how we understand emotions and perceive reality, opens the door to a young field in psycholinguistics; Extending on the one hand the knowledge regarding the role of aging in the understanding of language, and on the other hand, providing evidence regarding the importance of working emotional aspects in healthy aging programs which aim at the development of cognitivebehavioral coping skills and the achievement of significant goals.

\section{Acknowledgements}

This article was sponsored by the Conicyt National Scholarship program related to the Linguistics Doctoral program. University of Concepción. ID number 21170718.

\section{Conflict of interest}

Authors declare there is no conflict of interest in publishing the article.

\section{References}

1. De Vega M. Cerebro Cuerpo y Significado. Lección Inaugural del Curso Académico 2010-2011 Universidad de la Laguna, España, Spain; 2010. 
2. Vallejo RF. El rol de la emoción en la comprensión de textos narrativos Psicoperspectivas Individuo y Sociedad. 2012;1(1):125-140.

3. Márquez GM. Nuevas herramientas para la intervención psicológica con personas mayores: la tercera generación de terapias conductuales. Revista Española de Geriatría y Gerontología. 2010;45(5):247-249.

4. Iacub R. Las emociones en el curso de la vida Un marco conceptual. Kairós Gerontologia. Revista da Faculdade de Ciências Humanas e Saúde. 2013;16:15-39.

5. Carstensen L, Fung H, Charles S. Socioemotional selectivity theory and the regulation of emotion in the second half of life. Motivation and emotion. 2003;27(2):103-123.

6. Carstensen LL. The influence of a sense of time on human development. Science. 2006;312(5782):1913-1915.

7. Mauss I, Gross J. Emotion suppression and cardiovascular disease: Is hiding feelings bad for your heart? In: LR Temoshok, et al. editor Emotional expression and health: Advances in theory, assessment and clinical applications. New York, USA; 2004. p. 62-81.
8. Kellough J, Knight B. Positivity effects in older adults' perception of facial emotion: The role of future time perspective. The Journals of Gerontology Series B: Psychological Sciences and Social Sciences. 2012;67(2):150-158.

9. Charles S, Carstensen L. Unpleasant situations elicit different emotional responses in younger and older adults. Psychol Aging. 2008;23(3):495-504

10. León I, Díaz JM, Vega M, et al. Discourse-based emotional consistency modulates early and middle components of event-related potentials. Emotion. 2010;10(6):863-873.

11. Slachevsky A, Arriagada P, Maturana J, et al. Enfermedad de Alzheimer y otras demencias en Chile. Propuesta de un Plan Nacional de Alzheimer y otras demencias. 2016 